\title{
Philippe RYGIEL (coordonné par), « Réfugié(e)s »
}

Le mouvement social, $n^{\circ} 225,2008,158$ pages

\section{Linda Guerry}

\section{(2) OpenEdition}

Journals

Édition électronique

URL : https://journals.openedition.org/clio/10143

DOI : 10.4000/clio.10143

ISSN : 1777-5299

Éditeur

Belin

Édition imprimée

Date de publication : 1 mai 2011

Pagination : 304-305

ISBN : 978-2-8107-0157-5

ISSN : 1252-7017

Référence électronique

Linda Guerry, «Philippe rygiel (coordonné par), «Réfugié(e)s » », Clio. Femmes, Genre, Histoire [En ligne], 33 | 2011, mis en ligne le 01 mai 2013, consulté le 26 avril 2022. URL : http://journals.openedition.org/ clio/10143; DOI : https://doi.org/10.4000/clio.10143

Ce document a été généré automatiquement le 26 avril 2022.

Tous droits réservés 


\section{Philippe RYGIEL (coordonné par), « Réfugié(e)s »}

Le mouvement social, $\mathrm{n}^{\circ} 225,2008,158$ pages

Linda Guerry

\section{RÉFÉRENCE}

Philippe RYGIEL (coordonné par), « Réfugié(e)s », Le mouvement social, n²25, 2008, 158

pages

Revue attentive à l'histoire des femmes et du genre depuis la fin des années 1970, Le mouvement social consacre son dernier numéro de 2008 à l'histoire des réfugié(e)s. Ce volume fait partie de la série de publications regroupant en partie des textes présentés au colloque international Histoire, Genre et Migration (Mondes atlantiques, $\mathrm{XIX}^{\mathrm{e}}$ et $\mathrm{xx}^{\mathrm{e}}$ siècles) qui s'est tenu à Paris en mars 2006. Si le titre du numéro marque le genre féminin entre parenthèses, cinq des six articles portent principalement sur l'aspect féminin de l'exil. En ouverture, l'éditorial de Philippe Rygiel intitulé «Du genre de l'exil », soulignant la multiplication récente des études sur les exodes de populations et les politiques internationales et étatiques qui les concernent, précise que les articles choisis privilégient l'« expérience migrante, structurée par un statut - ou son absence ainsi que par les circonstances de la migration " principalement en Europe (un article concerne l'Égypte) du xix siècle au début des années 2000, en portant une attention particulière à la présence des femmes et au genre.

2 En guise d'introduction, le premier article de l'historien belge Frank Caestecker présente l'évolution des relations entre les réfugiés et les États européens aux XIX et $\mathrm{Xx}^{\mathrm{e}}$ siècles. Identifiant les différents moments de cette histoire (de la défense des réfugiés politiques à la crise de l'asile à partir des années 1980), l'auteur montre que la politique du refuge est un constant compromis entre les intérêts de l'État et les valeurs de protection des individus menacés par un pouvoir arbitraire, valeurs héritées du libéralisme du XIX siècle. À partir de sources non encore exploitées (notamment 
épistolaires), l'article de Sylvie Aprile propose une relecture sexuée de l'exil des proscrits français outre-Manche et outre-Atlantique au lendemain du coup d'État du 2 décembre 1851. Par l'analyse des représentations et du vécu de ces femmes, l'auteure identifie trois figures féminines majeures liées à l'exil : l'épouse de l'exilé restée au pays, la «suiveuse ", et l'exilée qui, au même titre que les hommes, part se réfugier à l'étranger. L'article montre notamment la participation des exilées au mouvement des femmes qui s'internationalise, même si, comme pour les hommes, l'exil est bien souvent synonyme de désengagement politique. La contribution d'Aurélie Audeval propose une approche genrée de la catégorisation nationale et montre, à travers l'exemple des réfugiées du $\mathrm{III}^{\mathrm{e}}$ Reich en France, «la différence pouvant exister entre la réalité numérique d'un phénomène et l'importance qui lui est donnée par les pouvoirs publics ». Dans un contexte où ces réfugiées arrivent en France et où l'action politique des femmes se développe, les mariages (peu fréquents) entre Allemandes et Français ont en effet suscité des craintes importantes, ces femmes appartenant à la nation ennemie et pouvant devenir françaises par ce biais. Le remarquable article de Silvia Salvatici analyse l'opération Balt Cygnet (1946-1947), l'un des premiers programmes de « réinstallation» dans un nouveau pays des personnes déplacées pendant la Seconde Guerre mondiale. Ce programme a concerné des milliers de femmes originaires des pays baltes en provenance des camps d'Allemagne, placées comme femmes de service dans des sanatoriums britanniques en partie pour des raisons économiques. L'auteure analyse les critères de sélection de ces femmes (nationalité, âge, situation matrimoniale) et met aussi en évidence, dans le processus de sélection, le rôle important des représentations, notamment l'idée que ces femmes sont politiquement moins dangereuses que des hommes. Dans une approche plus classique, Karine Meslin analyse les mutations des représentations et des rôles sexués et leurs conséquences dans le cas de l'exil cambodgien en France à partir de 1975. L'auteure montre, par exemple, que les rapports de sexe sont moins figés dans l'enceinte des domiciles privés que dans le cadre associatif communautaire et conclut à une double injonction d'adaptation à la société française et de fidélité aux origines, pointant les tensions qui en résultent chez certaines femmes. Dans le dernier article du numéro, Fabienne Le Houérou présente les résultats d'une enquête conduite en 2005 sur des femmes du Darfour en exil au Caire. Les stratégies de survie de ces femmes et leurs activités professionnelles, en comparaison avec celles des hommes, témoignent, dans une société égyptienne où elles font face à des préjugés racistes, d'une inventivité et d'une agency qui leur est propre et leur permet une mise à distance plus grande avec les atrocités qu'elles ont vécues. Explorant des territoires et des périodes divers, ce numéro démontre sans conteste les vertus heuristiques d'une approche qui prend en compte les femmes et le genre dans l'analyse du refuge et de ses politiques. 